\title{
WINTER WARMING FROM LARGE VOLCANIC ERUPTIONS
}

\author{
Alan Robock and Jianping Mao
}

Department of Meteorology, University of Maryland, College Park

Abstract. An examination of the Northern Hemisphere winter surface temperature pattems after the 12 largest volcanic eruptions from 1883-1992 shows warming over Eurasia and North America and cooling over the Middle East which are significant at the $95 \%$ level. This pattern is found in the first winter after tropical eruptions, in the first or second winter after midlatitude eruptions, and in the second winter after high latitude eruptions. The effects are independent of the hemisphere of the volcanoes. An enhanced zonal wind driven by heating of the tropical stratosphere by the volcanic aerosols is responsible for the regions of warming, while the cooling is caused by blocking of incoming sunlight.

\section{Introduction}

The eruption of Mt. Pinatubo on June 15, 1991, was possibly the most sulfur-rich of this century, putting about $20 \mathrm{Mt}$ of $\mathrm{SO}_{2}$ into the stratosphere [Bluth et al., 1991]. Although conventional wisdom holds that volcanic aerosols produce cooling at the surface due to reduction of incoming solar radiation (and indeed that effect is to be expected on a global average on a two- to three-year time scale [Robock, 1991]), the winter of 1991-92 was extremely warm over North American and Eurasian midlatitudes, and very cold in the Middle East. Here we present evidence that this pattern of warming and cooling was due to the volcano. An indirect dynamical mechanism in which stronger zonal winds are produced by an enhanced poleto-equator temperature gradient in the lower stratosphere caused by aerosol heating is responsible.

It was first suggested by Groisman [1985] that warm winters over central Russia were a consequence of large volcanic eruptions. Using surface air temperature data for stations in Europe (including the European part of Russia) and northeastern North America for averages of 2 or 3 winters after the volcanic years of $1815,1822,1831,1835$, $1872,1883,1902,1912$, and 1963, he showed a significant warming over the central European part of Russia, and insignificant changes in the other regions, including

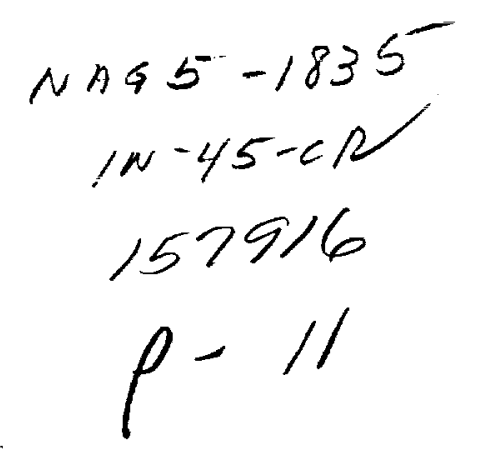


cooling over northeastern North America. In a recent update, Groisman [1992] showed the winter patterns after the $1982 \mathrm{El}$ Chichón and 1991 Pinatubo eruptions and found warming over Russia again, but found warming over northeastern North America. He explained the warming over Russia as due to enhanced zonal winds bringing warm maritime air from the north Atlantic over the continent, and that these winds were due to a larger pole-to-equator temperature gradient caused by polar cooling resulting from the eruptions.

While these studies are intriguing, they raise several questions. If the larger pole-to-equator temperature gradient was caused by polar cooling, why are the temperatures warm in the polar region over Eurasia, not cool? Why is northeastern North America cool after some eruptions and warm after others? What are the volcanic patterns over the rest of the world? How much of the signal found is due to volcanoes and how much to $\mathrm{El}$ Niño/Southern Oscillation (ENSO) events?

Lough and Fritts [1987], using tree-ring data and selecting 24 volcanic years between 1602 and 1900, found winter warming over western North America for the average of years 0 to 2 after the eruption years. The pattern they found is quite similar to that during ENSO years, and they made no attempt to correct for this factor. They also found spring and summer cooling in the central United States and summer warming over the United States west coast. They did not use any volcanoes south of $10^{\circ} \mathrm{S}$, believing them not important for Northern Hemisphere (NH) temperature variations.

Graf [1992] and Graf et al. [1992] presented results from a perpetual January general circulation model (GCM) calculation of the effects of stratospheric aerosols on climate that showed winter warming over both Eurasia and North America, and cooling over the Middle East, Africa, and the United States. The forcing used in this GCM experiment was a stratospheric aerosol loading in the pattern of the El Chichón volcano. The mechanism producing the warming was an enhanced polar vortex caused by warming in the tropical stratosphere of approximately $5^{\circ} \mathrm{C}$ from absorption of solar radiation by the volcanic aerosol. The stratospheric wind anomaly propagated down into the troposphere producing the patterns found. In the lower latitudes, the direct effect of reducing the solar flux resulted in cooling. However, in the high latitudes, due to the weak solar insolation, the dynamical effect dominated producing warming. 
In an attempt to comprehensively examine the winter surface temperature response to volcanoes, and to explain and reconcile the above results, this study looks at the response of $\mathrm{NH}$-winter-average surface temperature following each large volcanic eruption since 1883 . We examined the global surface temperature patterns and corrected for the ENSO signal. We chose to start the study in this year because before this time the global surface temperature data set has such a sparse distribution that it is too difficult to discern a pattern. We first explain how we chose the volcanoes, and then describe the surface temperature data and how they were analyzed.

\section{Volcanoes}

Volcanic eruptions which are rich in sulfur gases produce long-lasting stratospheric aerosol layers which cause global-average stratospheric warming and surface cooling for several years. These effects can be regional for a few months following the eruption while the aerosol cloud is inhomogeneous, but in less than a year the cloud becomes fairly uniformly distributed and produces no discernible regional forcing, with one exception. In the winter, the winter hemisphere has very little insolation, so the stratospheric warming is confined to the tropics and the summer hemisphere. Hence the only spatially-varying forcing is an enhanced pole-to-equator temperature gradient in the winter hemisphere. The aerosol cloud from tropical eruptions appears in the tropical stratosphere within months, but takes on the order of a year to reach the tropics from mid- and high latitude eruptions.

In order to decide which volcanoes to use, we examined the dust veil index (DVI) [Lamb, 1970, 1977, 1983; Robock, 1991] and the volcanic explosivity index (VEI) [Simkin et al., 1981, Newhall and Self, 1982; Bluth et al., 1991; Self, personal comm.]. Because these indices both have well-known problems [Robock, 1991], we examined all available ice core, astronomical, and geological records, but they were insufficient to define a clearly better index. We therefore took the conventional approach used in dozens of other studies [Robock, 1991] and chose volcanoes which had DVI (d.v.i./ $\left.E_{\max }\right) \geq 250$ or VEI $\geq 5$ (Table 1). 
The best global surface temperanure data set has been produced by the Climatic Research Unit of the University of East Anglia [Jones et al., 1986a, 1986b, 1986c; Jones, 1988] and updated to include global surface air temperature observations over land and sea surface temperatures from ship observations [Jones et al., 1991; Houghton et al., 1990]. We used this data set of monthly average, gridded surface temperatures, updated through July, 1992, which was kindly provided by Phil Jones. The data set consists of temperature anomalies with respect to the mean for the period 1951-1980.

In order to remove the influence of long-term variations, including the warming observed from the beginning of the record to the end, we used a high-pass Lanczos filter [Duchon, 1979] to remove variations with a time-scale greater than 10 years at each grid point. We also wanted to remove the ENSO signal, and so, by correlating temperature anomalies with the standardized Southern Oscillation Index [Chen, 1982; Ropelewski and Jones, 1987], also kindly provided by Phil Jones, with a lag of 2 months over the ocean and 4 months over the land, we subtracted out the portion of the signal that was correlated with ENSO. In this way, we can interpret our results as solely a volcanic signal, although this simple procedure to remove ENSO effects may still leave in some non-linear effects.

\section{Northern Hemisphere Winter Volcanic Signal}

Because of our understanding of how the volcanic aerosol should affect $\mathrm{NH}$ winter temperatures, we examined the first winter after the tropical volcanoes (Krakatau, Santa Maria [including the effects of Pelee and Soufriere the same year], Agung, Fuego, El Chichón, and Mt. Pinatubo) and the second winter after the high latitude volcanoes (Ksudach, Katmai, and Bezymianny) to allow the aerosol time to reach the ropical stratosphere. For the midlatitude volcanoes (Tarawera, Bandai, and Quizapu) we also chose the second winter, except that the pattern for Tarawera manifested itself in the first winter, so we chose that one. Evidently the aerosol from the Tarawera enuption reached the tropics during the first year. Since the results are the average of 12 volcanoes, this choice does not affect the basic conclusions. Note that we chose volcanoes from both the NH and Southern Hemisphere (SH), and only sorted them according to absolute value of latitude.

The resulting $\mathrm{NH}$ winter (DJF) surface temperature patterns for each volcano are shown in Figure 1 along with 
the average for the 12 volcanoes. In all 12 cases, a region of warming is seen over northern Eurasia and over North America. Figure 2 shows the average for the 12 volcanoes and the regions that are statistically significantly different from the average of the winters for all the other years between 1866 and 1992 at the 95\% level according to a Student's t-test. The warming over northern Eurasia and North America is significant at this level. There is a large region of cooling over northem Africa, the Middle East and southern Asia, portions of which are significant at the 95\% level. The North American warming is not an unremoved ENSO remnant, since there is no ENSO signal in this average in the tropical Pacific Ocean.

Because the $1947 \mathrm{Hekla}\left(64^{\circ} \mathrm{N}\right)$ eruption was not considered large (DVI = 70, VEI = 4), and the $1980 \mathrm{Mt}$. St. Helens $\left(46^{\circ} \mathrm{N}\right)$ eruption (DVI $=500$, VEI $=5$ ) had a small stratospheric input, we did not include the subsequent winters in our average, but they both had a very strong pattern that closely matches the others shown in Figures 1 and 2. Several of the eruptions that we included, Bandai, Fuego, and Bezymianny, are of questionable global significance because of their small DVI, VEI, or geological evidence, so we repeated the analysis without them and got essentially the same results, with significant warming over northern Eurasia and North America.

As a further test of the significance of the winter pattern (Figure 2), we subjectively examined every winter from 1866 through 1992. Out of the 127 winters, 39 had patterns similar to that in Figure 2, including all the 12 winters in this paper and 3 of the winters immediately following these. Thus, this pattern can occur without volcanic eruptions (in $21 \%$ of the non-volcanic years), but large volcanic eruptions cannot occur without producing this pattern.

\section{Discussion and Conclusions}

The NH winter surface temperature pattern found after large volcanic eruptions almost exactly matches the pattern found in the perpetual January general circulation model (GCM) calculation of the effects of stratospheric aerosols on climate [Graf, 1992; Graf et al., 1992]. The warming over both Eurasia and North America, and the cooling over the Middle East are all seen in the GCM output. The patterns also match the European pattern found by Groisman [1985, 1992] and the North American pattern found by Lough and Fritts [1987]. Thus we conclude that

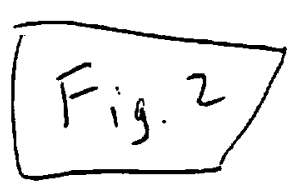


winter warming over Northern Hemisphere mid- and high latitudes and subtropical cooling are indeed volcanic effects to be expected in the winter following large tropical volcanoes, in the first or second winter following midlatitude volcanoes, and in the second winter following high latitude volcanic enuptions from either hemisphere. The forcing caused by heating of the tropical stratosphere produces anomalously strong zonal winds in the mid- and high latitudes which advect warmer maritime air over the continents, producing the warming. In the tropics and subtropics, the direct effects of blocking of solar radiation by the aerosols produces cooling.

The effects of the mid- and high latitude volcanoes do not depend on the hemisphere of the volcano. For both $\mathrm{NH}$ and $\mathrm{SH}$ volcanoes, after the aerosol reaches the tropics, the dynamical feedback produces winter warming over $\mathrm{NH}$ continents. In the $\mathrm{SH}$, the lack of continents in the mid- and high latitudes prevents the warming effect from happening in the $\mathrm{SH}$ winter.

We examined the other seasons after volcanic eruptions and found no other significant regional responses. The remarkable cooling in eastern and central North America and warming in the west in the spring and summer of 1992, while agreeing with the results of Lough and Fritts [1987], are evident in our data, but not at a significant level.

The winter warming in certain locations and globalaverage cooling that lasts for several years are characteristic features of the climatic system response to volcanic eruptions that must be considered when interpreting the climatic record. In order to understand the response to ENSO events and greenhouse warming these patterns must be taken into account.

Acknowledgments. We thank Phil Jones for surface temperature and SOI data; Karl Taylor, Anandu Vernekar, and Hans Graf for valuable discussions; Pasha Groisman for an insightful review; and Brian Doty for development and enhancements of the GrADS plotting software, which was used for both the figures. This work was supported by NSF and DOE under grant ATM 89-20590 and NASA grant NAG 5-1835.

\section{References}

Bluth, G. J. S., S. D. Doiron, C. C. Schnetzler, A. J. Krueger, and L. S. Walter, Global tracking of the $\mathrm{SO}_{2}$ 
clouds from the June, 1991 Mount Pinatubo eruptions, Geophys. Res. Lett., 19, 151-154, 1992.

Chen, W. Y., Assessment of Southern Oscillation sea level pressure indices, Mon. Wea. Rev., 110, 800-807, 1982.

Duchon, C. E., Lanczos filtering in one and two dimensions, J. Appl. Meteor., 18, 1016-1022, 1979.

Graf, H.-F., Volcanoes and climate - results of GCM experiments, paper presented at AGU Chapman Conference on Climate, Volcanism and Global Change, Hilo, Hawaii, March 23-27, 1992.

Graf, H.-F., I. Kirchner, A. Robock and I. Schult, Pinatubo eruption winter climate effects: model versus observations, Report No. 94, 24 pp., Max-Planck-Institut fur Meteorologie, Hamburg, Germany, 1992.

Groisman, P. Ya., Regional climatic consequences of volcanic eruptions (in Russian), Meteorology and Hydrology, No. 4, 39-45, 1985.

Groisman, P. Ya., Possible regional climate consequences of the Pinatubo eruption: an empirical approach, $\mathrm{Geo}$ phys. Res. Lett., 19, 1603-1606, 1992.

Houghton, J. T., G. J. Jenkins, and J. J. Erasmus (Eds.), Climate Change The IPCC Scientific Assessment, 365 pp., Cambridge Univ. Press, Cambridge, 1990.

Jones, P. D., Hemispheric surface air temperature variations: recent trends and an update to 1987, J. Climate, 1, 654-660, 1988.

Jones, P. D., S. C. B. Raper, R. S. Bradley, H. F. Diaz, P. M. Kelly and T. M. L. Wigley, Northern Hemisphere surface air temperature variations: 1851-1984, J. Clim. and Appl. Meteor., 25, 161-179, 1986a.

Jones, P. D., S. C. B. Raper, and T. M. L. Wigley, Southem Hemisphere surface air temperature variations: 1851-1984, J. Clim. and Appl. Meteor., 25, 1213$1230,1986 \mathrm{~b}$.

Jones, P. D., S. C. B. Raper and T. M. L. Wigley, Global temperature variations between 1861 and 1984, Nature, 322, 430-434, 1986c.

Jones, P. D., T. M. L. Wigley, and G. Farmer, Marine and land temperature data sets: a comparison and a look at recent trends, in Greenhouse-Gas-Induced Climatic Change: A Critical Appraisal of Simulations and Observations, edited by M. E. Schlesinger, pp. 153172, Elsevier, Amsterdam, 1991.

Lamb, H. H., Volcanic dust in the atmosphere; with a chronology and assessment of its meteorological significance, Phil. Trans. Roy. Soc. London, A266, 424-533, 1970. 
Lamb, H. H., Supplementary volcanic dust veil index assessments, Climate Monitor, 6, 57-67, 1977.

Lamb, H. H., Update of the chronology of assessments of the volcanic dust veil index, Climate Monitor, 12, 79-90, 1983.

Lough, J. M. and H. C. Fritts, An assessment of the possible effects of volcanic eruptions on North American climate using tree-ring data, 1602 to 1900 A.D., Climatic Change, 10, 219-239, 1987.

Newhall, C. G. and S. Self, The volcanic explosivity index (VEI) - an estimate of explosive magnitude for historical volcanism, J. Geophys. Res., 87, 1231-1238, 1982.

Robock, A., The volcanic contribution to climate change of the past 100 years, in Greenhouse-Gas-Induced Climatic Change: A Critical Appraisal of Simulations and Observations, edited by M. E. Schlesinger, pp. 429-444, Elsevier, Amsterdam, 1991.

Ropelewski, C. F. and P. D. Jones, An extension of the Tahiti-Darwin Southern Oscillation Index, Mon. Wea. Rev., 115, 2161-2165, 1987.

Simkin, T., L. Siebert, L. McClelland, D. Bridge, C. Newhall and J. H. Latter, Volcanoes of the World, 240 pp., Hutchinson Ross, Stroudsburg, PA, 1981.

Jianping Mao and Alan Robock, Department of Meteorology, University of Maryland, College Park, Maryland 20742

(Received August 31, 1992;

Accepted November 2, 1992.)

Copyright 1992 by the American Geophysical Union.

Paper number 92L5125D.

Robock and Mao: Winter Warming from Large Volcanoes

Robock and Mao: Winter Warming from Large Volcanoes

Robock and Mao: Winter Warming from Large Volcanoes 
Fig. 1. Northern Hemisphere winter (DJF) surface temperature anomalies for the indicated years (the winter following the tropical volcanic eruptions, the first or second winter following the midlatitude eruptions, and two winters following the high-latitude ones), and the average of the 12 cases.

Fig. 2. Average of the 12 winter surface temperature anomalies shown in Fig. 1 (same as last map in Fig. 1, but with contour interval $=0.5^{\circ} \mathrm{C}$ ), with shading indicating the regions for which this average is significantly different from the average of the winters for all the other years between 1866 and 1992 at the 95\% level according to a Student's t-test.

TABLE 1. List of 12 largest volcanoes since 1883.

\begin{tabular}{lcccc}
\hline Volcano & Eruption Year & Lat. & d.v.i./ $E_{\max }$ & VEI \\
\hline Krakatau & 1883 & $6^{\circ} \mathrm{S}$ & 1000 & 6 \\
Tarawera & 1886 & $38^{\circ} \mathrm{S}$ & 800 & 5 \\
Bandai & 1888 & $38^{\circ} \mathrm{N}$ & 500 & 4 \\
Santa Maria & 1902 & $15^{\circ} \mathrm{N}$ & 600 & 6 \\
Ksudach & 1907 & $52^{\circ} \mathrm{N}$ & 500 & 5 \\
Katmai (Novarupta) & 1912 & $58^{\circ} \mathrm{N}$ & 500 & 6 \\
Quizapu (Cerro Azul) & 1932 & $36^{\circ} \mathrm{S}$ & 70 & 5 \\
Bezymianny & 1956 & $56^{\circ} \mathrm{N}$ & 30 & 5 \\
Agung & 1963 & $8^{\circ} \mathrm{S}$ & 800 & 4 \\
Fuego & 1974 & $14^{\circ} \mathrm{N}$ & 250 & 4 \\
El Chichón & 1982 & $17^{\circ} \mathrm{N}$ & 800 & 5 \\
Mt. Pinatubo & 1991 & $15^{\circ} \mathrm{N}$ & 1000 & 6 \\
\hline
\end{tabular}


Krakatau 1883-84

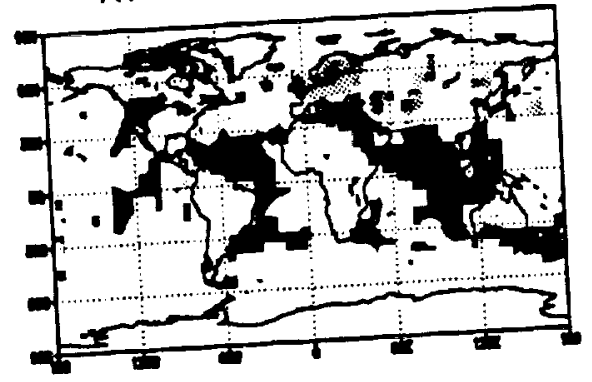

Santa Maria 1902-03

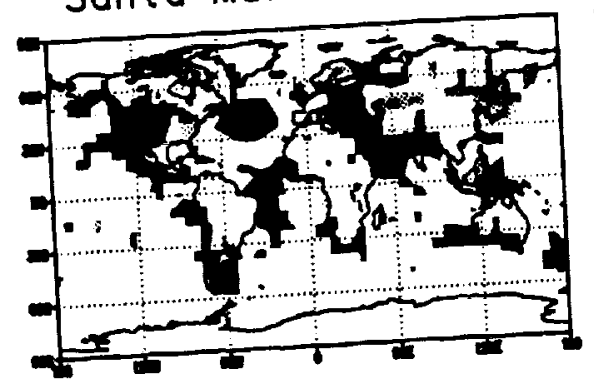

Quizapu 1933-34

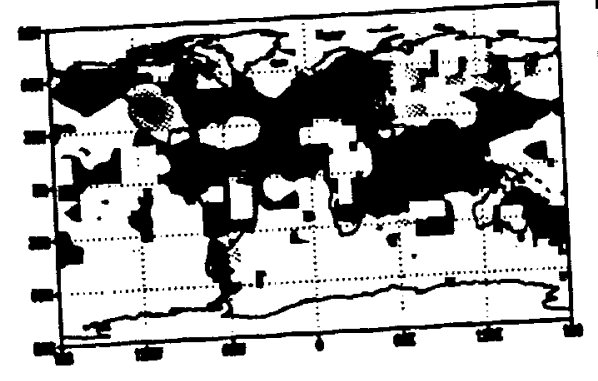

Fuego 1974-75

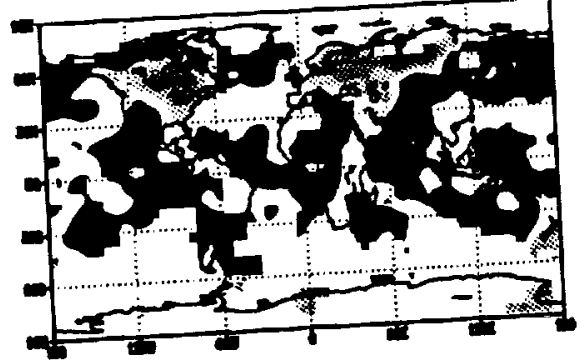

Average of 12 cases

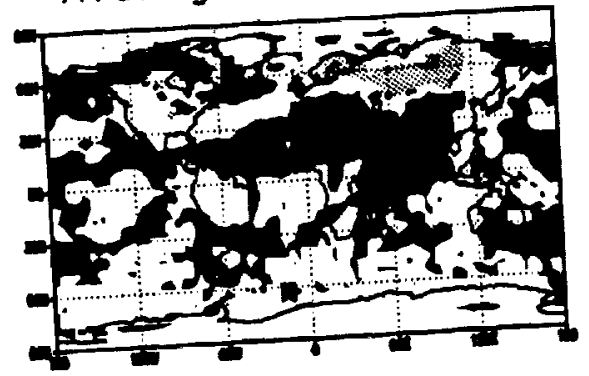

Tor awera 1886-87

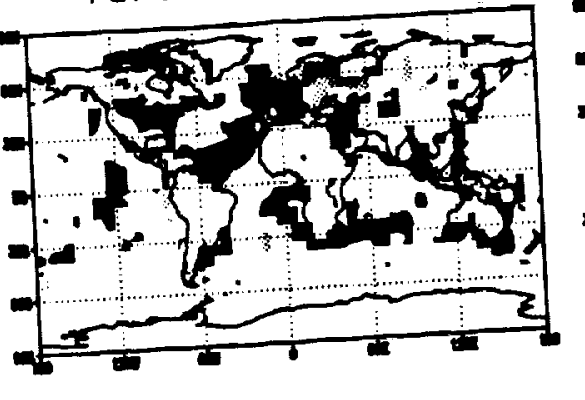

Ksudach 1908-09

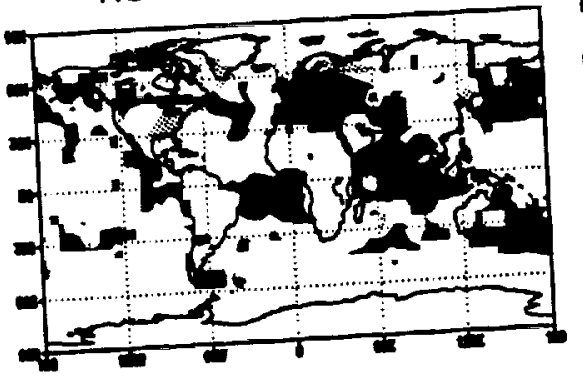

Bezymi anny 1957-58

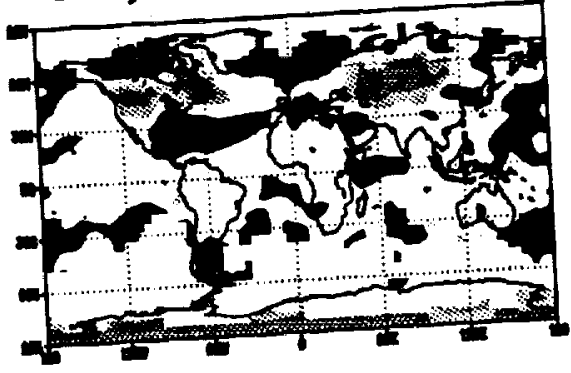

El Chichón 1982-83

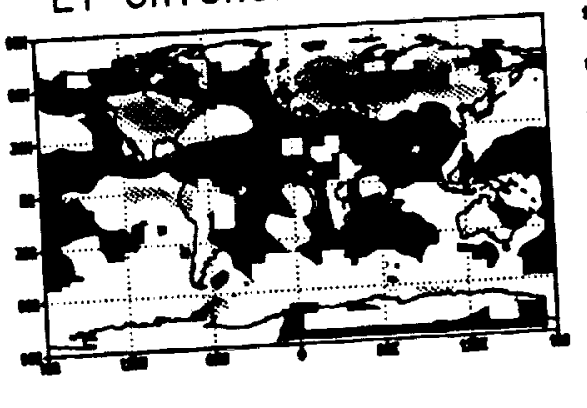

Banda i 1889-90

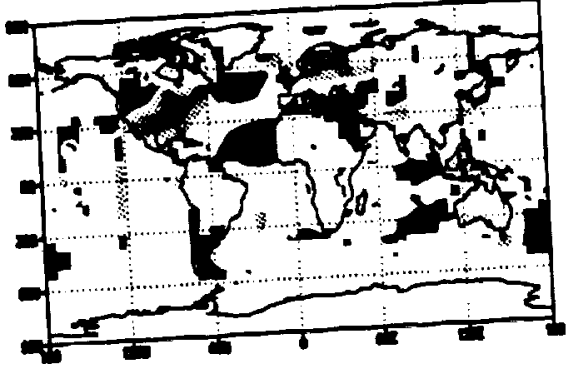

Kotmai 1913-14

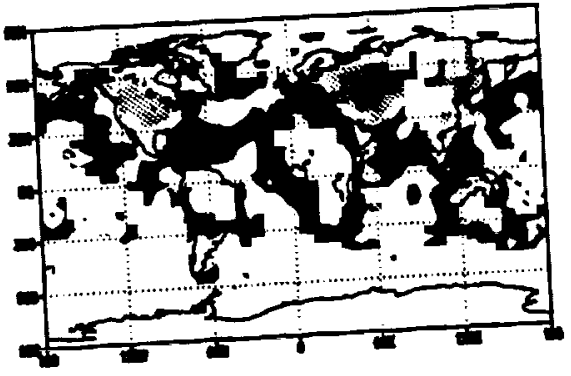

Agung 1963-64

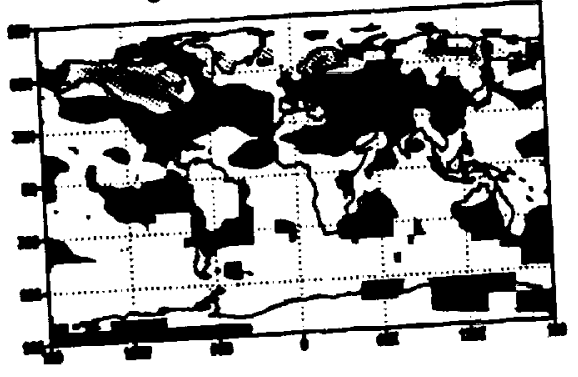

Pinatubo 1991-92

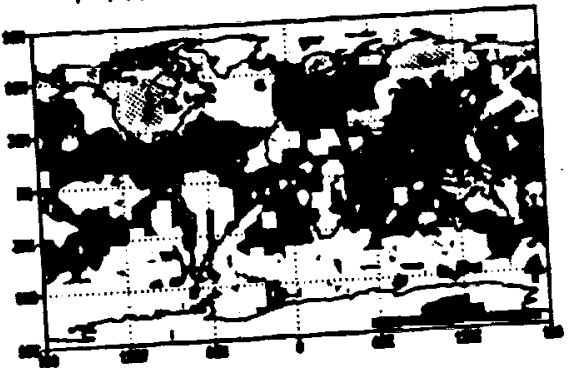

NH Winter (DJF)

Surface Temperature Anomalies (K)

$<-3 \quad-3 \quad-2 \quad-1 \quad 0+1+2+3 \geq+3$ 


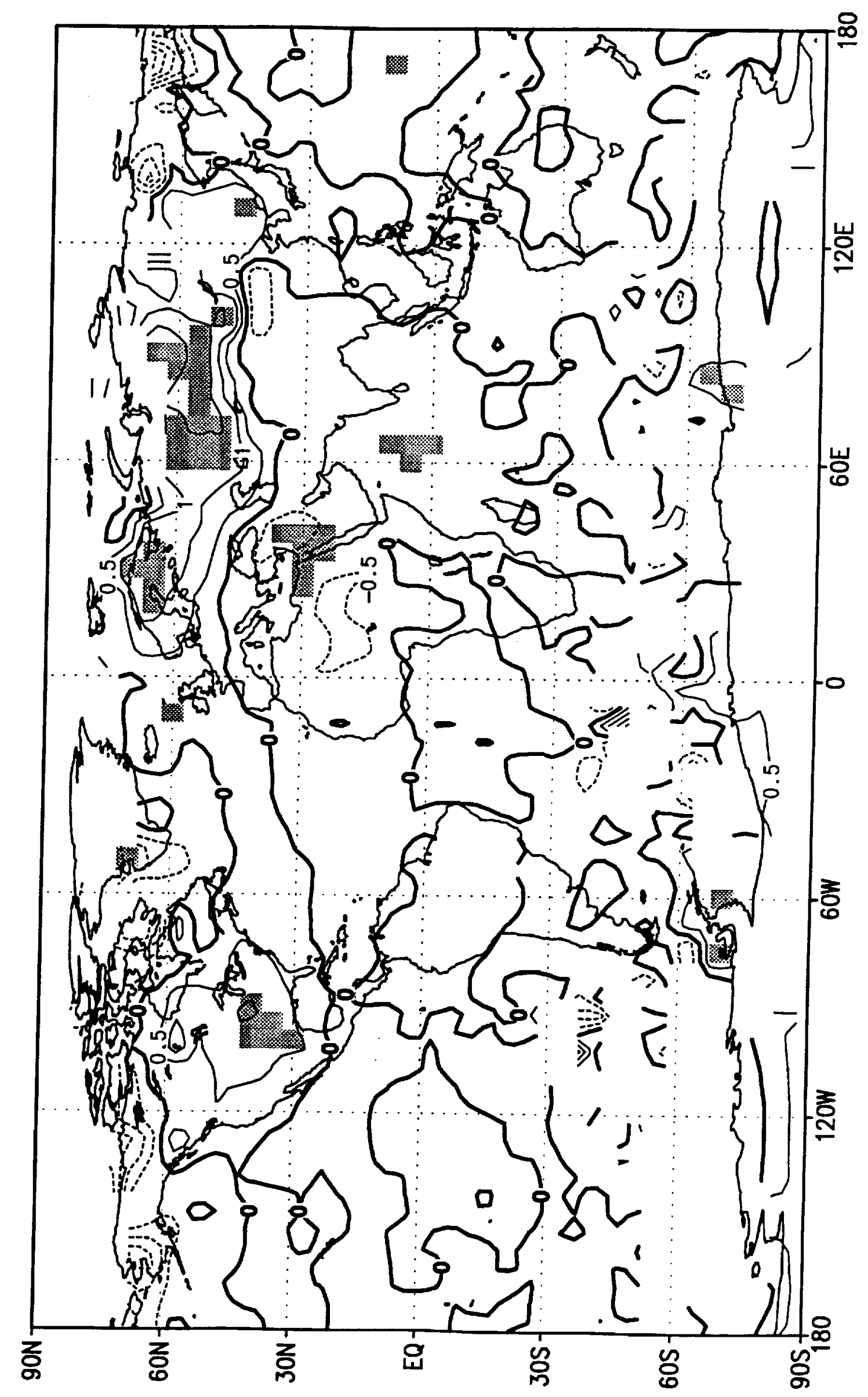

